\title{
AN APPROACH TO MODELING AND THERMODYNAMIC ANALYSIS OF MODERN POWER ENGINEERING SYSTEMS
}

\author{
Jarosław Kozaczka ${ }^{*}$, Pavel Kolat ${ }^{2}$ \\ ${ }^{1}$ AGH - University of Science and Technology, al. Mickiewicza 30, 30-059 Kraków, Poland \\ ${ }^{2} \mathrm{VŠB}$ - Technical University of Ostrava, 17 listopadu 15/2172, 70833 Ostrava-Poruba, Czech \\ Republic
}

The new efficient method of modeling and thermodynamic analysis of power engineering systems has been presented. With its help a comparison of different structures and investigation of the influence of a particular constituent process onto the whole system efficiency is possible. The shaft work or the exergy is the main thermodynamic quantity taken into account in analyses, and the appropriate dimensionless modeling parameter has been introduced.

Keywords: thermodynamics, modeling, exergy, power engineering, CCS

\section{INTRODUCTION}

Power systems become more and more complex, Kolat et al. (2008). Their inner structure is therefore more and more like the inner structure of chemical engineering processes. The systems should be analysed and optimised by means of a suitable method. The problem is, however, that power engineering systems differ significantly from their process and chemical engineering counterparts. For the latter many efficient analyses and optimisation methods have been worked out, and although they are often criticised, their application allows attain the expected goals. A very good example is the Linnhoff's approach — his discussion e.g. in Linnhoff (1993) — which is widely sold and applied as computer software.

The significant and in fact decisive difference between power engineering and process and chemical engineering systems results from their appropriation: the first are build to get maximum energy output, and the second ones to get maximum substance output. While in the first case emissions will be minimised, i.e. the substance output, in the second case the energy consumption of the system, e.g. energy supply will be held at a minimum. The minimum amounts of substance and energy should be understood as the optimised quantities due to the overall costs analysis, Fig. 1.

One of the reasons why power systems have become more complex is demand to decrease $\mathrm{CO}_{2}$ emissions, e.g. Fig. 2., or in general, emissions of the so-called green house effect gases. There is not enough evidence for the earth's climate changes caused by these emissions, e.g. Bradley (2004), but the current law forces appropriate research. The economy is the main guideline and although electricity production by zero $\mathrm{CO}_{2}$ emission is ca. $60 \%$ more expensive than in an ordinary power plant, $\mathrm{CO}_{2}-$ trading forces investigations of new solutions. 
Process \& Chemical

Engineering System

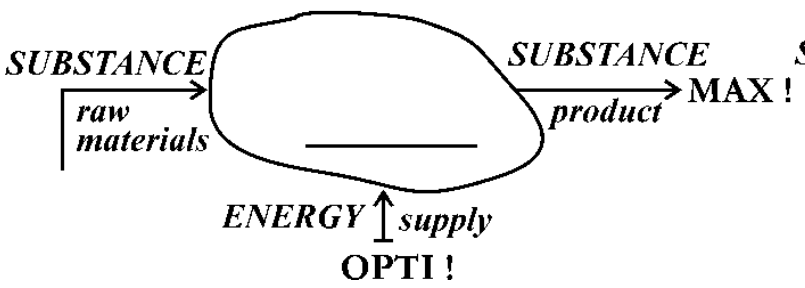

Power

Engineering System

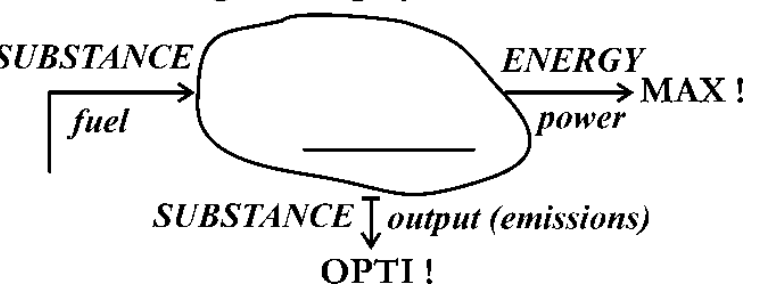

Fig. 1. Process \& Chemical Engineering System vs. Power Engineering System

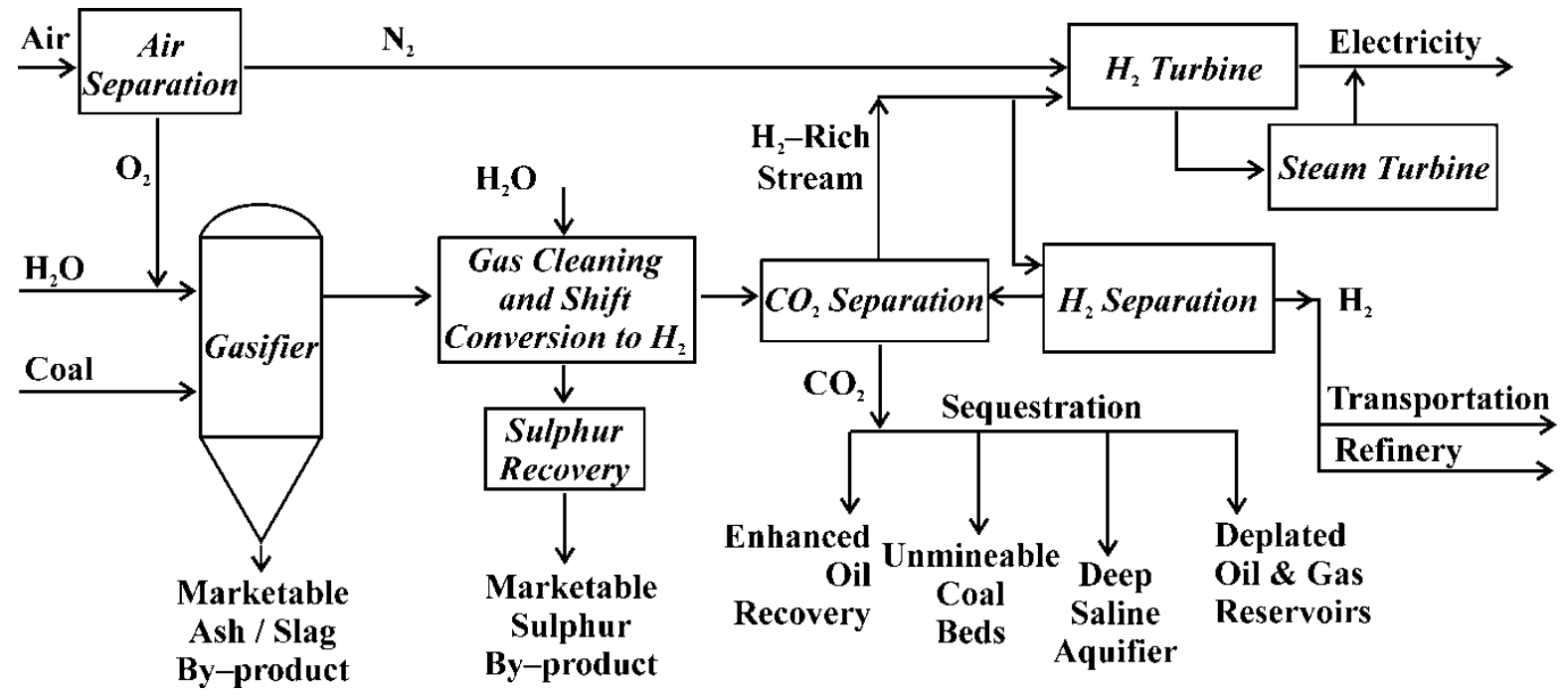

Fig. 2. USA Project FutureGen (should be ready in 2012 at cost of ca. 870 bilion $\$$ )

The system of clean coal combustion in power stations is a new technology that should be considered. The last decisions of the European Union provide for ca. $20 \% \mathrm{CO}_{2}$ emissions reduction till 2020. Thus, the problem is a very urgent one. In fact modernisation of the existing systems is the most effective way to reduce these emissions in power stations. At the overall efficiency of $30 \%$ the coal fired unit emits ca. $33 \%$ more $\mathrm{CO}_{2}$ per year than the unit at the efficiency improved up to $45 \%$, which is easy to determine for the standard coal. But the new $\mathrm{CO}_{2}$-free techniques are discussed and already tested in a pilot scale at the same time, because any improvement has its limits. Thus, in the next future the clean (or so-called $\mathrm{CO}_{2}$-free) coal combustion power systems should be considered. Already some pilot plants have been built to broaden the experience on the subject.

There are three main methods of $\mathrm{CO}_{2}$-free combustion systems: (1) Pre-Combustion, (2) OxyFuel, and (3) Post-Combustion.

The first one, the Integrated Gasifying Combined Cycle (IGCC) is presented in Fig. 3. Its advantages are the highly efficient cycle technology applied for coal combustion and the possibility of by-products recovery. In fact, proven processes are used, e.g. absorption, which is very well known from process and chemical engineering. Disadvantages, however, are technological complexity, not yet competitive availability and price and higher fuel consumption than in a conventional power plant technology. Additionally, air separation process can be used for applying water steam/oxygen gasifying procedure.

The second technology, the so-called OxyFuel is presented in Fig. 4. Its advantages are: it is based on proven processes and high $\mathrm{CO}_{2}$ output concentration allows a very efficient separation. Disadvantages, 
however, are: more complex than conventional combustion technologies, additional costs for air separation (oxygen production) and again higher fuel consumption that in conventional combustion techniques.

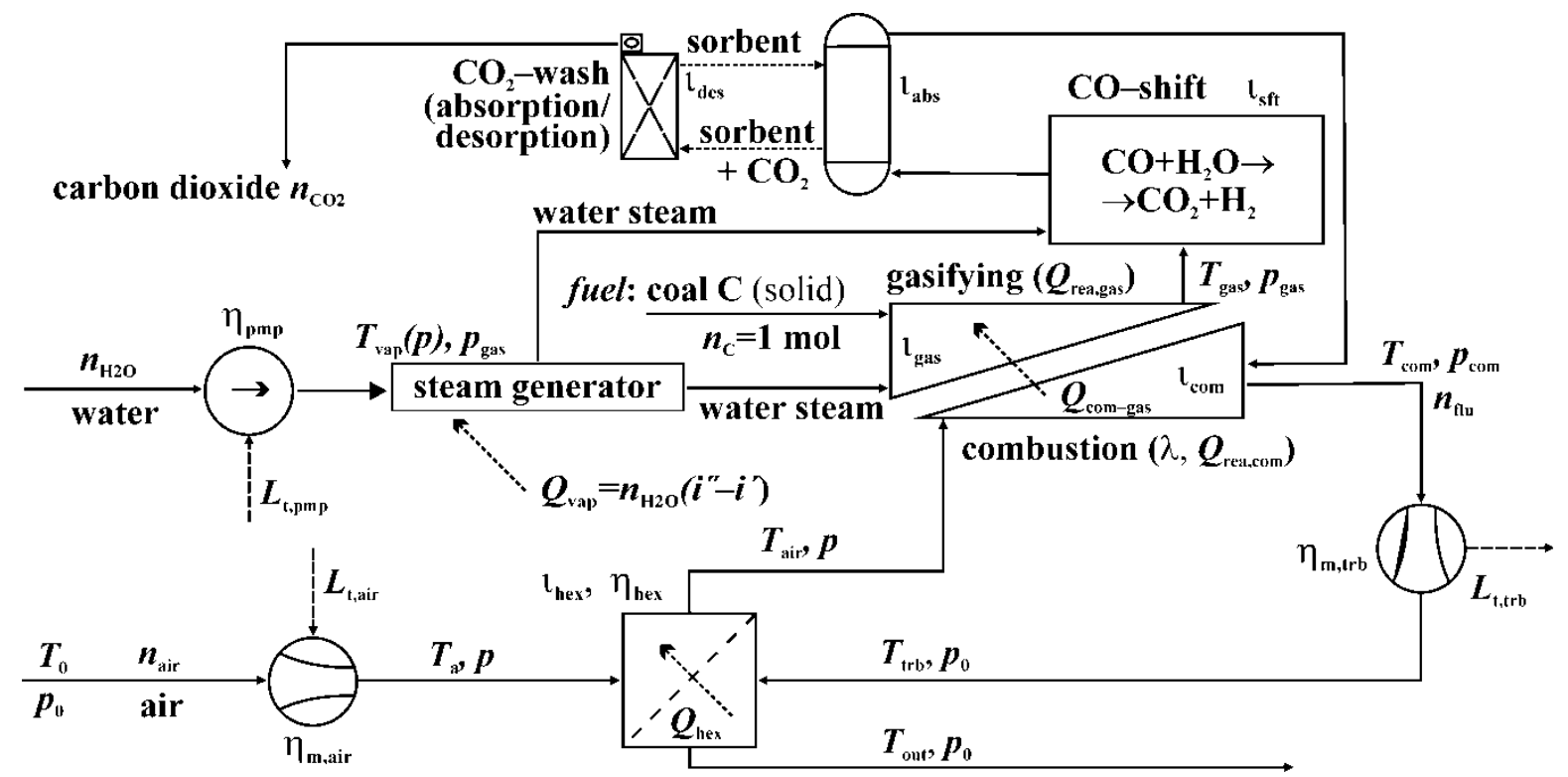

Fig. 3. The Integrated Gasifying Combined Cycle (IGCC)

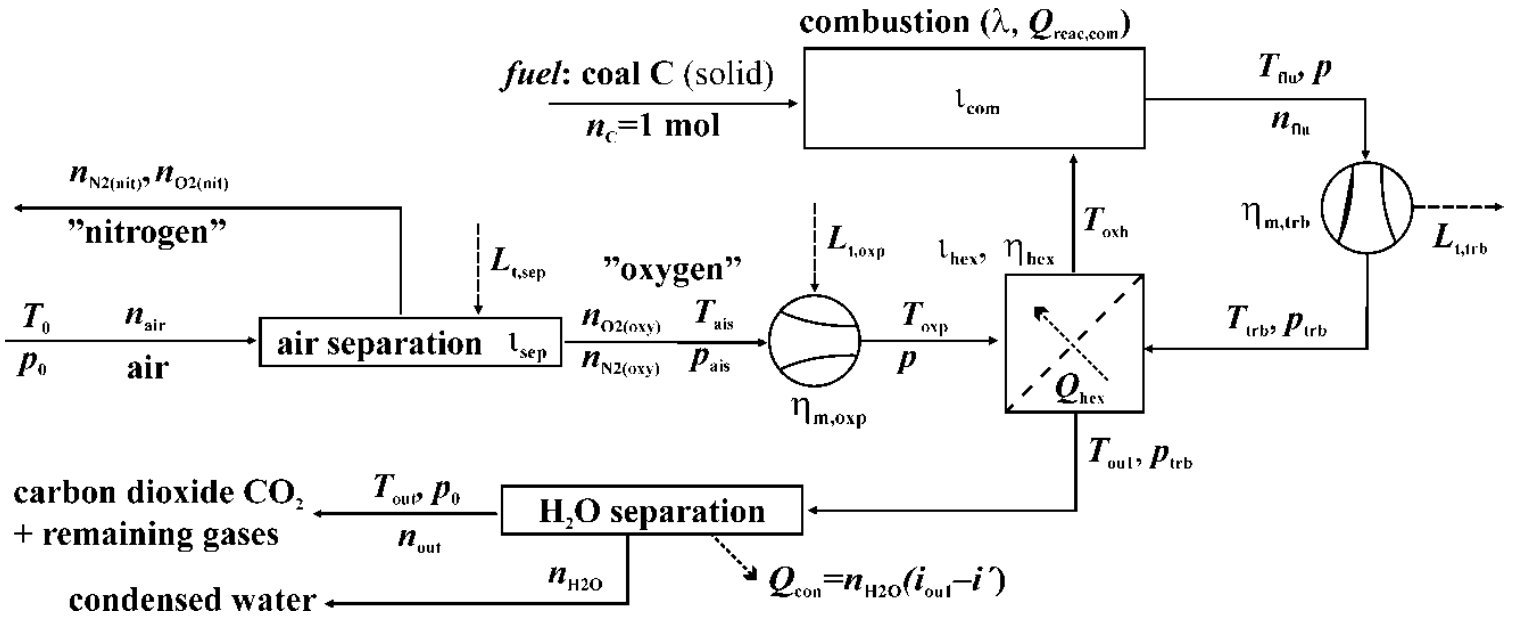

Fig. 4. The OxyFuel System of clean coal combustion

Last, but not least technology is the so-called Post-Combustion Process, Fig. 5. Its advantages are: the system is based on known and proven processes (e.g. absorption). The disadvantages, however, are: greater complexity than conventional combustion, very high auxiliary consumption for amine regeneration and higher fuel consumption that in conventional technologies.

In Figs 3.-5. systems of gas turbines are showed, but conclusions will be the same as for water steam conventional power units. The most important goal of analyses is to express special characteristics of the discussed modern power technologies and the most important output energy which in fact is the exergy (or the shaft work). The energy of a power engine is its exergy as the maximum technical (shaft) work that can be obtained from the given kind of energy (e.g. heat) in the natural environment.

In the first and the third technology the absorption/desorption process, the so-called $\mathrm{CO}_{2}-\mathrm{wash}$, is applied. It is a very sensitive process because of very hard conditions it should run in a power station 
system, especially in the post-combustion technology. But it should be stated that the first pilot plants built are the post-combustion ones. Recently some advances are to be noted in $\mathrm{CO}_{2}$ absorption technology, e.g. the so-called GenosorbN developed by the German company Clariant GmbH (Burgkirchen), tested lately at the Universities of Dresden and Halle/Saale, Ohle et al. (2004).

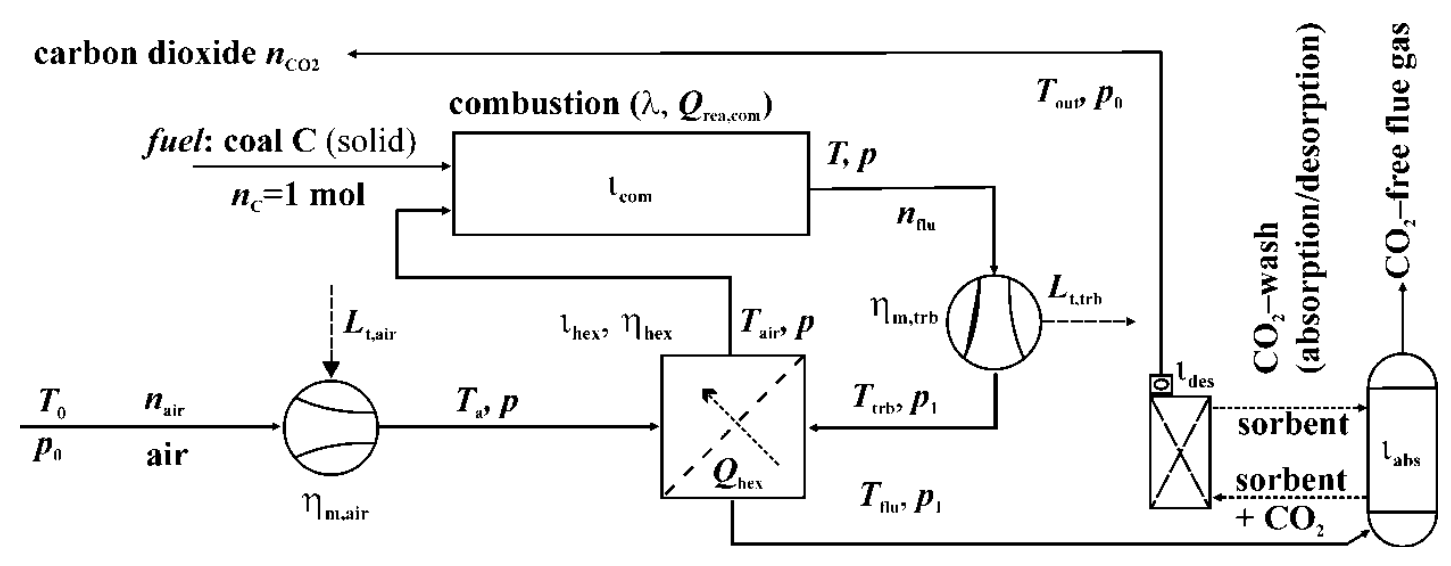

Fig. 5. Post-Combustion Process (PCP)

\section{AN APPROACH TO MODELING}

The modeling approach should be strictly oriented to thermodynamic analyses. The basics of such a method have been worked out in the research team of Professor Wolfgang Fratzscher, Kozaczka (1981), (1988), and later on developed and tested many times, e.g. Kozaczka and Kolat (2004), (2005), (2006). The most powerful modeling approach uses dimensionless parameters of numerical values between 0 and 1 that can univocally determine the process applied in practice.

Processes that are part of complex technological systems, especially power engineering ones, can be divided into: (1) working (or pressure changing) processes; (2) equilibrium approaching processes; (3) supporting (or coupling) processes.

Working processes are the most popular pressure changing processes in compressors and turbines with or without heat exchange with surroundings (cooling by compression, heating up by expansion). Equilibrium approaching processes are all heat and substance exchange processes in heat exchangers and absorbers (desorbers) and chemical reactions. To the last group belong such processes as simple water vaporisation to obtain water steam (e.g. for chemical reactions), throttling, etc.

After detailed analyses have been made it could be stated that for univocal determining of pressure changing processes in compressors and turbines the obviously known polytropic efficiency is very useful. With its help the main thermodynamic parameters of the most important working processes can be calculated: the useful (i.e. technical or shaft) work, heat exchanged and irreversibilities, cf. Klenke (1978), Haupt (1980), Traupel (1977).

The characteristic dimensionless coefficient for a transfer process, suitable for modeling purposes, is the so-called process intensity , Kozaczka (1981). It takes into account how the real process differs from the perfect process, in which the equilibrium could be reached. In other words, it gives information about the process kinetics in an indirect manner.

The intensity dimensionless coefficient for heat transfer (exchange) processes is defined by 


$$
l_{\text {hex }}=\frac{Q}{Q^{*}} \quad \text { or } \quad \iota_{\text {hex }}=\frac{Q}{Q_{\infty}}
$$

where $Q$ is the heat transferred (exchanged), $Q^{*}$ the heat transferred (exchanged) until the equilibrium has been reached, and $Q_{\infty}$ is the same as $Q^{*}$, but written down as the heat exchanged on the infinitely large apparatus. It can be generally distinguished between co-current and counter-current. The latter one is the usually applied media guidance.

Additionally, one more dimensionless coefficient can be formulated that takes into account heat losses to the surroundings. Basically they are very low, but they can be expressed by the energy (or thermal) efficiency, just like the quotient

$$
\eta_{\text {hex }}=\frac{Q_{\mathrm{C}}}{Q_{\mathrm{H}}}
$$

where $Q_{\mathrm{H}}$ is the heat supplied by the hot (subscript $H$ ) medium, and $Q_{\mathrm{C}}$ the heat absorbed by the cold (subscript $C$ ) one. Usually temperatures (or in general parameters) at the start of a process are known, depending on the system analysed. Solving Equations (1) and (2) simultaneously gives appropriate results for the discussed process. The same approach can be applied in the case of substance transfer processes, e.g. for absorption.

The combustion (or gasifying) process will be determined by the reaction intensity parameter, which can be calculated as a quotient

$$
l_{\text {rea }}=\frac{\xi}{\xi^{*}}
$$

whereby $\xi$ is an extent of a chemical reaction (according to Denbigh (1987), or reactions coordinate according to Smith and Van Ness (1987)). The superscript asterisk stands for the state of equilibrium. Numerical values of $\xi$ vary from zero (no reaction) to $\xi=\xi^{*}$ (equilibrium). The extent of a chemical reaction in a differential form is defined by

$$
d \xi=\frac{d n_{\mathrm{A}}}{\left|v_{\mathrm{A}}\right|}=\frac{d n_{\mathrm{B}}}{\left|v_{\mathrm{B}}\right|}=\frac{d n_{\mathrm{C}}}{\left|v_{\mathrm{C}}\right|}=\ldots \quad \text { or } \quad \xi=\frac{\Delta n_{\mathrm{A}}}{\left|v_{\mathrm{A}}\right|}=\frac{\Delta n_{\mathrm{B}}}{\left|v_{\mathrm{B}}\right|}=\frac{\Delta n_{\mathrm{C}}}{\left|v_{\mathrm{C}}\right|}=\ldots
$$

If the reaction intensity parameter $\mathrm{l}_{\text {rea }}$ equals to zero, there is no process. If it, however, equals one, the equilibrium state will be reached. After computing the value of $\xi^{*}$ in an equilibrium state, both the „real" extent of reaction and appropriate quantities of reactants in a resulting reacting mixture can be determined.

The given modeling approach is valid for all types of simple chemical reactions, i.e. for the so-called $=$ type and the $\rightarrow$ type reactions, homogeneous and heterogeneous ones. For simultaneous chemical reactions, however, the method becomes too complex (especially for more than two), e.g. Kozaczka (2007).

One more advantage of the approach is that the main distinctive dimensions of the device or apparatus can be almost directly predicted, and the process given by those dimensionless parameter (polytropic efficiency or intensity, respectively) should be run in the apparatus. Thus, the very important and in fact decisive investment and operation costs analysis can be undertaken without any further assumptions, e.g. Kozaczka (1974), Haupt and Kozaczka (1984).

In Figs 3.-5. appropriate dimensionless parameters for particular processes are shown: polytropic efficiencies $\eta_{\mathrm{m} \text {,air }}$ for air compressor and $\eta_{\mathrm{m} \text {,trb }}$ for gas turbine (alternatively $\eta_{\mathrm{pmp}}$ for water pumping, which can be treated as an ordinary pump efficiency), and intensities $\mathrm{l}_{\mathrm{abs}} / \mathrm{l}_{\mathrm{des}}$ for absorption/desorption, $t_{\text {hex }}$ for technological heat exchange (or additionally $\eta_{\text {hex }}$ as the thermal efficiency taking into account 
heat losses). The following intensities characteristic for chemical reactions are shown in these Figures: $\mathfrak{l}_{\text {com }}$ for simplified combustion (the $\rightarrow$ type reaction), $\mathfrak{l}_{\text {gas }}$ for gasifying (the =type reaction), and $\mathbf{l}_{\mathrm{sft}}$ for the shift reaction. The intensity parameters do not lead to chemical reactors dimensioning but they do determine their geometry ensuring expected process kinetics.

Many tests have led to the conclusion that the modeling approach presented above is very clear, plain and reliable - it does not need any special calculation methods.

\section{AN APPROACH TO THERMODYNAMIC ANALYSIS}

Energy balance is the essential one to agree all the energy kinds in a system. For thermodynamic rating of the whole system the energy and exergy efficiency can be used. For complex systems, however, the system sensitivity due to particular processes is interesting. It means the degree of an influence of a particular process onto the whole system is important: knowing the sensitivity analysis makes a practical study possible. It can be stated which process is to improve or which process should be conducted with a special care. For the purpose the concept of the so-called thermodynamic effectivity is very useful.

It is in general given by

$$
\varepsilon=\frac{\sum E_{\mathrm{j}}^{+}}{\sum E_{\mathrm{i}}^{-}}
$$

whereby it results from the exergy balance in a form

$$
\sum E_{\mathrm{i}}^{-} \rightarrow \sum E_{\mathrm{j}}^{+}+T_{0} \Delta S_{\text {irr }}
$$

This equation shows that in an analysed process there are $i$ disappearing (superscript - ) and $j$ created (superscript + ) exergies. It does not mean, however, that the equality sign should be placed instead of a pointer: every term of the classical exergy balance can consist both of disappearing and created exergies, e.g. Rant (1964), Kozaczka (2002), and lately Kozaczka and Kolat (2010). Joining all the disappearing and created exergies, which occur in complex systems of an unrestricted structure, consisting of $m$ constituent processes,

$$
\sum\left(\sum E_{\mathrm{i}}^{-}\right)_{\mathrm{m}} \rightarrow \sum\left(\sum E_{\mathrm{j}}^{+}\right)_{\mathrm{m}}+T_{0} \Delta S_{\text {irr }}
$$

the thermodynamic effectivity of this complex technological system is

$$
\varepsilon_{\Sigma}=\frac{\sum\left(\sum E_{\mathrm{j}}^{+}\right)_{\mathrm{m}}}{\sum\left(\sum E_{\mathrm{i}}^{-}\right)_{\mathrm{m}}}
$$

or

$$
\varepsilon_{\Sigma}=\sum_{\mathrm{m}} \frac{\left(\sum E_{\mathrm{j}}^{+}\right)_{\mathrm{m}}}{\sum\left(\sum E_{\mathrm{i}}^{-}\right)_{\mathrm{m}}}=\sum_{\mathrm{m}}\left(\frac{\left(\sum E_{\mathrm{i}}^{-}\right)_{\mathrm{m}}}{\sum\left(\sum E_{\mathrm{i}}^{-}\right)} \cdot \frac{\left(\sum E_{\mathrm{j}}^{+}\right)_{\mathrm{m}}}{\left(\sum E_{\mathrm{i}}^{-}\right)_{\mathrm{m}}}\right)=\sum_{\mathrm{m}} \gamma_{\mathrm{m}} \varepsilon_{\mathrm{m}}
$$

whereby

$$
\gamma_{\mathrm{m}}=\frac{\left(\sum E_{\mathrm{i}}^{-}\right)_{\mathrm{m}}}{\sum\left(\sum E_{\mathrm{i}}^{-}\right)_{\mathrm{m}}}
$$

is a mathematical weight coefficient of the in $m$-th process disappearing exergies. The main disadvantage of the presented method is that the thermodynamic effectivity quotient approaches the 
value of one if it contains a very large number of constituent processes. E.g. for infinite process number it yields

$$
\lim _{\mathrm{m} \rightarrow \infty} \varepsilon_{\Sigma}=1
$$

independently of the Second Law irreversibilities. Thus

$$
\gamma_{\mathrm{m}} \rightarrow 0
$$

On the contrary, for a system consisting of only one process it will be

$$
\lim _{\mathrm{m} \rightarrow 1} \varepsilon_{\Sigma}=\varepsilon_{\mathrm{m}} \quad \text { or } \quad \gamma_{\mathrm{m}} \rightarrow 1
$$

respectively. It is obvious that this circumstance confirms the correctness of the presented method. In Kozaczka (2002) the way of overcoming difficulties in applying exergy analysis has been discussed. Nevertheless, the decisive advantage of the method presented above is the possibility of investigating a complex system's sensitivity using the mathematical weight coefficients $\gamma_{\mathrm{m}}$. Moreover, the last analysis can be made for different values of natural environment intensities, especially the temperature $T_{0}$. Computations of simplified power systems containing chemical reactions of combustion and gasifying have confirmed this statement and pointed out the correctness and usefulness of such analyses.

\section{SOME NUMERICAL RESULTS}

Hitherto tests using simple programming languages (MathCAD) have proved the value of the method for the first project-step analyses. For the IGCC coal combustion system showed schematically in Fig. 3. results have been obtained for different gasifying/combustion pressures and temperatures. The gasifying reaction $\mathrm{C}+\mathrm{H}_{2} \mathrm{O}=\mathrm{CO}+\mathrm{H}_{2}$ and combustion ones $\mathrm{CO}+1 / 2 \mathrm{O}_{2} \rightarrow \mathrm{CO}_{2}$ and $\mathrm{H}_{2}+1 / 2 \mathrm{O}_{2} \rightarrow \mathrm{H}_{2} \mathrm{O}$ have been taken into account. Besides, calculations have been made for different modeling dimensionless parameters $\eta$ and $\iota$. For a somehow simplified IGCC system (without CO-shift reaction and $\mathrm{CO}_{2}-$ wash) the multidimensional optimisation has been undertaken, but because of the lack of appropriate mathematical methods and computer power, trials have been foreseen for later tests. In fact the main data obtained can be enough for comparing and choosing a system structure for later and more detailed analyses.

Numerical results for an example of such simplified IGCC system have been presented in Kozaczka et al. (2006) - the calculation procedure would exceed the volume and goal of this paper but it is very simple (it was the main assumption of the modeling approach elaboration). The most interesting issue is the sensitivity analysis, i.e. how does the total system efficiency depend on the particular process efficiency. The efficiencies are expressed by the appropriate thermodynamic effectivity quotients. All the dimensionless parameters are set to 0.9 , i.e. $l_{\text {gas }}=0.9, l_{\text {com }}=0.9, \eta_{p m p}=0.9, \eta_{m, \text { air }}=0.9, \eta_{m, t r b}=0.9$, $\eta_{h e x}=0.9, \iota_{h e x}=0.9$ : the comparison can be then made for different main thermodynamic parameters (temperature and pressure) and the appropriate dimensionless ones. Calculations have been made for the natural environment $T_{0}=298 \mathrm{~K}$ and $p_{0}=10^{5} \mathrm{~Pa}$.

From the Table 1 and Table 2 it can be stated how the particular process affects the total energy conversion effectivity. E.g. the gasifying process is the decisive one because of the greatest numerical value of the mathematical weight $\gamma_{\text {gas. }}$. Appropriate comparisons can be made using results for the whole range of useful thermodynamic (temperature and pressure) and dimensionless modeling parameters.

Numerical values of the total exergy efficiency $\eta_{\mathrm{ex}}$ and of the energy one $\eta_{\text {th }}$ are inessential for presenting the method. 
Table 1. Thermodynamic effectivities of particular system's processes and their influence onto the total system thermodynamic effectivity for $T_{\text {gas }}=1100 \mathrm{~K}, p=10^{6} \mathrm{~Pa}, T_{\text {com }}=1500-1900 \mathrm{~K}$

\begin{tabular}{|l|c|c|c|c|c|c|}
\hline \multirow{2}{*}{$T_{\text {gas }}$} & \multicolumn{5}{|c|}{$T_{\text {com }}$} \\
\cline { 3 - 7 } & & $1500 \mathrm{~K}$ & $1600 \mathrm{~K}$ & $1700 \mathrm{~K}$ & $1800 \mathrm{~K}$ & $1900 \mathrm{~K}$ \\
\hline \multirow{3}{*}{ water pump $p=10^{6} \mathrm{~Pa}$} & $\varepsilon_{\text {pmp }}$ & 0.900 & 0.900 & 0.900 & 0.900 & 0.900 \\
\cline { 2 - 7 } & $\gamma_{\text {pmp }}$ & $2.076 \cdot 10^{-5}$ & $2.097 \cdot 10^{-5}$ & $2.114 \cdot 10^{-5}$ & $2.128 \cdot 10^{-5}$ & $2.141 \cdot 10^{-5}$ \\
\hline \multirow{2}{*}{$\begin{array}{l}\text { water steam } \\
\text { generation }\end{array}$} & $\varepsilon_{\text {vap }}$ & 0.507 & 0.5 & 0.493 & 0.487 & 0.482 \\
\cline { 2 - 7 } & $\gamma_{\text {vap }}$ & 0.033 & 0.033 & 0.034 & 0.035 & 0.035 \\
\hline \multirow{3}{*}{ gasifying } & $\varepsilon_{\text {gas }}$ & 0.991 & 0.991 & 0.991 & 0.991 & 0.991 \\
\cline { 2 - 7 } & $\gamma_{\text {gas }}$ & 0.389 & 0.393 & 0.396 & 0.399 & 0.401 \\
\hline \multirow{3}{*}{ combustion } & $\varepsilon_{\text {com }}$ & 0.925 & 0.935 & 0.944 & 0.951 & 0.957 \\
\cline { 2 - 7 } & $\gamma_{\text {com }}$ & 0.352 & 0.356 & 0.359 & 0.362 & 0.365 \\
\hline \multirow{2}{*}{ air compression } & $\varepsilon_{\text {air }}$ & 0.932 & 0.932 & 0.932 & 0.932 & 0.932 \\
\cline { 2 - 7 } & $\gamma_{\text {air }}$ & 0.056 & 0.050 & 0.044 & 0.040 & 0.036 \\
\hline \multirow{2}{*}{ turbine expansion } & $\varepsilon_{\text {trb }}$ & 0.900 & 0.900 & 0.900 & 0.900 & 0.900 \\
\cline { 2 - 7 } & $\gamma_{\text {trb }}$ & 0.154 & 0.149 & 0.144 & 0.140 & 0.137 \\
\hline \multirow{2}{*}{ heat exchange } & $\varepsilon_{\text {hex }}$ & 0.863 & 0.854 & 0.846 & 0.839 & 0.833 \\
\cline { 2 - 7 } & $\gamma_{\text {hex }}$ & 0.016 & 0.019 & 0.022 & 0.024 & 0.026 \\
\hline
\end{tabular}

Table 2. Thermodynamic effectivities of particular system's processes and their influence onto the total system thermodynamic effectivity for $T_{\text {gas }}=1300 \mathrm{~K}, p=2 \cdot 10^{6} \mathrm{~Pa}, T_{\text {com }}=1500-1900 \mathrm{~K}$

\begin{tabular}{|c|c|c|c|c|c|c|}
\hline \multirow{2}{*}{\multicolumn{2}{|c|}{$T_{\mathrm{gas}}=1300 \mathrm{~K}, p=2 \cdot 10^{6} \mathrm{~Pa}$}} & \multicolumn{5}{|c|}{$T_{\text {com }}$} \\
\hline & & $1500 \mathrm{~K}$ & $1600 \mathrm{~K}$ & $1700 \mathrm{~K}$ & $1800 \mathrm{~K}$ & $1900 \mathrm{~K}$ \\
\hline \multirow{2}{*}{ water pump } & $\varepsilon_{\mathrm{pmp}}$ & 0.900 & 0.900 & 0.900 & 0.900 & 0.900 \\
\hline & $\gamma_{\mathrm{pmp}}$ & $3.076 \cdot 10^{-5}$ & $3.097 \cdot 10^{-5}$ & $3.114 \cdot 10^{-5}$ & $3.128 \cdot 10^{-5}$ & $3.141 \cdot 10^{-5}$ \\
\hline \multirow{2}{*}{$\begin{array}{l}\text { water steam } \\
\text { generation }\end{array}$} & $\varepsilon_{\text {vap }}$ & 0.602 & 0.593 & 0.585 & 0.578 & 0.572 \\
\hline & $\gamma_{\text {vap }}$ & 0.021 & 0.022 & 0.023 & 0.024 & 0.024 \\
\hline \multirow{2}{*}{ gasifying } & $\varepsilon_{\text {gas }}$ & 0.987 & 0.987 & 0.987 & 0.987 & 0.987 \\
\hline & $\gamma_{\text {gas }}$ & 0.352 & 0.361 & 0.369 & 0.375 & 0.380 \\
\hline \multirow{2}{*}{ combustion } & $\varepsilon_{\mathrm{com}}$ & 0.926 & 0.935 & 0.944 & 0.950 & 0.956 \\
\hline & $\gamma_{\mathrm{com}}$ & 0.316 & 0.325 & 0.333 & 0.339 & 0.343 \\
\hline \multirow{2}{*}{ air compression } & $\varepsilon_{\mathrm{air}}$ & 0.940 & 0.940 & 0.940 & 0.940 & 0.940 \\
\hline & $\gamma_{\text {air }}$ & 0.102 & 0.090 & 0.081 & 0.072 & 0.065 \\
\hline \multirow{2}{*}{ turbine expansion } & $\varepsilon_{\text {trb }}$ & 0.900 & 0.900 & 0.900 & 0.900 & 0.900 \\
\hline & $\gamma_{\mathrm{trb}}$ & 0.209 & 0.201 & 0.194 & 0.189 & 0.183 \\
\hline \multirow{2}{*}{ heat exchange } & $\varepsilon_{\text {hex }}$ & - & - & - & 0.898 & 0.891 \\
\hline & $\gamma_{\text {hex }}$ & - & - & - & $1.013 \cdot 10^{-3}$ & $4.507 \cdot 10^{-3}$ \\
\hline
\end{tabular}




\section{CONCLUSIONS}

The approach presented above seems to be a very efficient and suitable tool for modeling and analysing complex technological systems. It can be useful for process and chemical engineering systems that are usually very complex and there are no known methods for their pure thermodynamic analysis, only combined ones are applied.

This work has been completed within the ENET project (Power Units for Utilization of non Traditional Energy Sources), CZ.1.05/2.1.00/03.0069.

\section{SYMBOLS}

$\begin{array}{ll}E & \text { exergy, } \mathrm{kJ} \\ i & \text { specific enthalpy, } \mathrm{kJ} / \mathrm{kg} \\ n & \text { mole number, } \mathrm{kmol} \\ p & \text { pressure, } \mathrm{MPa} \\ Q & \text { heat, } \mathrm{kJ} \\ S & \text { entropy, } \mathrm{kJ} /(\mathrm{kgK}) \\ T & \text { temperature, } \mathrm{K}\end{array}$

Greek symbols

$\begin{array}{ll}\gamma & \text { mathematical weight coefficient } \\ \varepsilon & \text { thermodynamic effectivity } \\ \eta & \text { efficiency } \\ l & \text { process intensity } \\ v & \text { stoichiometric coefficient } \\ \xi & \text { extent of a chemical reaction }\end{array}$

\section{Superscripts}

$\begin{array}{ll}* & \text { in state of equilibrium } \\ + & \text { input or positive value } \\ - & \text { output or negative value }\end{array}$

\section{Subscripts}

a air

$A, B, C \quad$ specie

air air compression

C cold (or coal)

com combustion

con condensation

flu flue gas

$H \quad$ hot

hex heat exchanger

gas gasifying

$i \quad$ disappearing

$j \quad$ created

$m \quad$ process number or polytropic

nit "nitrogen" stream

oxy "oxygen" stream

pmp water pump

rea chemical reaction 


$\begin{array}{ll}\text { trb } & \text { turbine expansion } \\ \text { ser } & \text { air separation } \\ \text { vap } & \text { water steam generation (vaporisation) } \\ 0 & \text { natural environment } \\ \Sigma & \text { total }\end{array}$

\section{REFERENCES}

Bradley R.L., 2004. Climate alarmism reconsidered. VŠB-TU Ostrava, Výzkumné energetické centrum, Ostrava (in Czech).

Denbigh K., 1987. The principles of chemical equilibrium. $4^{\text {th }}$ edition, Cambridge University Press, CambridgeNew York.

Haupt T., 1980. Fundamentals of thermodynamics. SU 743, AGH, Wydział Masz.Górn.Hutn., Inst.Masz.Hutn. i Automatyki, Kraków (in Polish).

Haupt T., Kozaczka J., 1984. The relation between the thermodynamic effectivity of a complex technological system and thermodynamic effectivities of its elements. In: Problemy Rozwojowe Silników Spalinowych, Instytut Okrętowy Politechniki Szczecińskiej, Szczecin, September 28 1984, 51-59 (in Polish).

Klenke J.W., 1978. Heat and work in thermodynamics. Brennst.-Wärme-Kraft (BWK) 30, 45-52 (in German).

Kolat P., Roubíček V., Kozaczka J., 2008. Modern power technologies - cycle efficiency, emission and economic analysis. A Comparative Study. VŠB-TUO, FS KE, Ostrava (in Czech).

Kozaczka J., 1974. Contribution to the investigation of the fixed costs dependence on thermodynamic quantities, MS Thesis. In: Beyer J. (Ed.), 1980. Energieanwendung 29, 182-186 (in German).

Kozaczka J., 1981. Thermodynamic analysis and rating of chemical engineering processes, Sektion Verfahrenstechnik, WB Technische Thermodynamik und Energiewirtschaft, TH Leuna-Merseburg, Merseburg (in German).

Kozaczka J., 1988. Thermodynamic analysis. Wydawnictwo AGH, SU 1110, Kraków (in Polish).

Kozaczka J., 2002. Thermodynamic analysis of energy conversion processes. Problems of Mechanical Engineering and Robotics No. 8, AGH - University of Science and Technology, Kraków.

Kozaczka J., 2007. Thermodynamic analysis and rating of modern power engineering systems. Vědecké spisy Fakulty strojní (Edice: Habilitační a inaugurační spisy, sv. 41), VŠB-TUO, Ostrava.

Kozaczka J., Kolat P., 2004. Thermodynamic approach to the combined coal utilization in a gasifyingcombustion process. Acta Mechanica Slovaca (Košice) 8 (3-A), 45-48.

Kozaczka J., Kolat P., 2005. Modeling and analysis of a clean coal combustion system, 10 ${ }^{\text {th }}$ International Conference on Environment and Mineral Processing. VŠB-TU Ostrava, Czech Republic, June 22-24 2005, Part I, 241-247.

Kozaczka J., Kolat P., 2010. Exergy and its applications. Monographs on Science and Education, TANT Publishers, Tarnów.

Kozaczka J., Kolat P., Wójcik G., 2006. Dimensionless parameters in modeling systems containing chemical reactions. 33 ${ }^{\text {rd }}$ Int.Conf. of Slovak Society of Chemical Engineering, Tatranské Matliare, Slovakia, May 22-26 2006, 52 (abstract); CD-Ref. 080p (full text).

Linnhoff B., 1993. Pinch analysis - A comparison. ENSEC'93, Energy Systems and Ecology, Cracow, Poland, July 5-9 1993, 1, 43-52.

Ohle A., Mollekopf N., Burchhardt U., Snell A., 2004. Comparison of various technologies of $\mathrm{CO}_{2}$-separation from flue and synthesis gases. XXXVI. Kraftwerkstechnisches Kolloquium, Dresden, Germany, October 19-20 2004, Tagungsband II, V44 (in German).

Rant Z., 1964. Exergy and anergy. Wiss.Z. TU Dresden 13, (M)- und (T)-Reihe, 34, 1145-1149 (in German).

Smith J.M., Van Ness H.C., 1987. Introduction to chemical engineering thermodynamics. $4^{\text {th }}$ edition, McGrawHill Book Company, New York.

Traupel W., 1977. Thermal turbomachinery. Band 1, 3. Aufl., Springer-Verlag, Berlin (in German). 